\title{
Conducting A Classroom Mini-Experiment Using An Audience Response System: Demonstrating The Isolation Effect
}

Melinda J. Micheletto, Ph.D., Saint Michael's College, USA

\begin{abstract}
The view of the learner has changed from that of a passive recipient of knowledge to that of an active constructor of knowledge. One way in which constructivism can manifest itself is by implementing active learning strategies where "knowledge [is] directly experienced, constructed, acted upon, tested, or revised by the learner." (Thompson \& Jorgensen, 1989). Classroom experiments can provide a stimulating active learning exercise for students being introduced to theories, concepts, and real life data. By actively participating in an experiment, students will better understand the concepts the experiment is designed to demonstrate, have fun, and be more involved in class. Using an audience response system to replicate theoretical studies, actual survey data, and social or economic experiments is useful as the results are displayed instantly (no need for the pen/paper method that requires out of class tabulation) and it allows for immediate discussion. Additionally, students' reflection of their experience in the experiment is a great way to encourage active learning and promote deeper, critical thinking.
\end{abstract}

Keywords: audience response system; active learning; constructivism; classroom experiment

\section{INTRODUCTION}

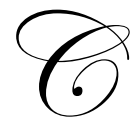

onstructivism is a theory about how people learn. In essence, it explains how people construct their own understanding and knowledge of the world through experiencing things and reflecting upon those experiences. In a classroom setting, the constructivist view of learning can lead toward a variety of different teaching methods. In general, it encompasses using active learning techniques (e.g., experiments) to create knowledge and offer opportunity to reflect on what is being learned.

Durham, McKinnon, and Schulman (2007) performed a comprehensive study of the efficacy of economics experiments in the classroom and concluded that classroom experiments improve student performance on test questions over the topics that the experiments covered. Additionally, exposure to economics experiments positively influenced student attitudes towards the study of economics (Durham et al., 2007; Emerson and Taylor, 2004).

This article focuses on using an audience response system to develop a classroom mini-experiment in which the students are active participants, not only in the experiment, but also in the analysis, discussion of results, and subsequent accumulation of knowledge. The use of an audience response system also allows an opportunity to show how the class data compared to data from published sources. Additionally, true to constructivist learning strategies, students can be given the chance to predict the outcome of an experiment before participating or before actual published data is revealed. Although not all theories or studies can be simulated in this manner, this article will introduce one scenario in which an audience response system was successfully used to conduct a miniexperiment and offer suggestions for other applications. 


\section{LITERATURE REVIEW}

\section{Constructivism}

Constructivism, as a philosophy of learning, is based on the work of philosopher, Giambattista Vico, who held that true understanding only occurs when learners construct the knowledge themselves. Many other individuals have worked with the idea of constructivism, but the first major contemporaries to develop a clear idea of constructivism as applied to classrooms and childhood development were Jean Piaget and John Dewey ("Constructing Knowledge in the Classroom").

For Dewey (1916), learning relies on active involvement; knowledge emerges from situations in which students have to extract ideas from experiences that have meaning and importance to them. He believed these conditions have to materialize in a social framework, such as a classroom, where students can join in discussion and, thus, create a community of learners who build their knowledge together. Piaget's (1973) view of constructivism is based on his fundamental belief that the basis of learning is discovery. In other words, the construction of knowledge is a dynamic process that requires the active engagement of the learner.

Constructivism is based on the principle that "learning is not a passive receiving of ready-made knowledge but a process of construction in which the students themselves have to be the primary actors" (von Glasersfeld, 1995, p. 120). Rather than passively receiving information, the learner actively interprets the information and reconciles it with his/her previous ideas and experience (Anthony, 1996). Therefore, the presumption of constructivism is that we, as learners, are responsible for our own learning and it is the teacher that is responsible for creating a supportive learning environment (Holzer, 1994). The view of the learner has changed from that of a passive recipient of knowledge to that of an active constructor of knowledge.

One way in which constructivism can manifest itself in the classroom is by implementing active learning strategies where "knowledge [is] directly experienced, constructed, acted upon, tested, or revised by the learner." (Thompson \& Jorgensen, 1989). In essence, constructivist learning dictates that the concept and idea follow the action, rather than precede it. Therefore, the activity is what leads to the concepts; the concepts do not lead to the activity (Cooperstein \& Kocevar-Weidinger, 2004).

The question then is, how does one go about designing a learning environment that promotes active learning? Authentic activities can be the foundation of many new learning environments that are concerned with active learning. Examples of authentic activities include, but are not limited to experiential learning (Kolb, 1984; Laws, 1991), collaborative learning (Beichner, 1993; Felder, Forrest, Baker-Ward, Dietz \& Mohr, 1993) contextbased learning (Lumsdaine \& Voitle, 1993), and computer-based learning (Laws, 1991; Shneiderman, 1993).

Various experiential learning techniques provide opportunities for students to learn by experiencing concrete examples of theoretical concepts (Dobbins, Boehlje, Erickson, \& Taylor, 1995). Often, these techniques have the additional benefit of increasing students' enthusiasm, motivation, interest, and curiosity (Koontz, Peel, Trapp, \& Ward, 1995) because the experiential learning environment creates a "need to know" on the part of the student (Dobbins et al., 1995).

According to Brooks and Brooks (1993), an effective constructivist classroom should incorporate the following practices:

- $\quad$ Encourage higher-level thinking. Challenge students to reach beyond simple factual answers and encourage them to connect and summarize concepts by analyzing, predicting, justifying, and defending their ideas.

- $\quad$ Engage students in experiences that challenge hypotheses and encourage discussion. When students are permitted to make predictions, they often produce varying hypotheses about natural phenomena.

- Use raw data, primary sources, physical, and interactive materials. The constructivist approach involves placing students in real-world scenarios and helping them generate the ideas that connect concepts together. 
Consequently, in the classroom, constructivism encourages students to use active techniques (experiments, real-world problem solving) to generate ideas and then to reflect on and discuss if and how their understanding is changing. ("Workshop: constructivism as a paradigm for teaching and learning," n.d.). Instructors who utilize constructivist methods can use raw data, primary sources, and interactive materials to provide experiences for their students rather than relying solely on another's set of data. For example, rather than read about the census, students can examine and interpret census data. Or, they plan a mini-census by gathering their own data and interpreting the results ("Constructing knowledge in the classroom," 1994). Or, rather than reading about the results of a social experiment, students can be active participants in the experiment and compare the class results to the actual study results.

\section{Classroom Experiments}

Demonstrations and experiments can be a powerful strategy to incorporate active learning into the classroom (Nattiv, 1994). Along with a verbal explanation, an experiment or demonstration can illustrate how a process occurs. Although slightly different in nature, demonstrations and experiments provide some of the same benefits to students and instructors alike. Demonstrations appear to be more common in the sciences, however, experiments can be found in many disciplines, including field science, business, and the social sciences.

Moll and Millner-Bolotin (2009) point out that demonstrations have a long history of playing an important role in the teaching in the sciences. However, demonstrations, when merely observed passively, may not have a significant impact on student learning (Crouch, Fagen, Callan, \& Mazur, 2004; Roth, McRobbie, Lucas, \& Boutonne', 1997). Students can frequently misinterpret the results or incorrectly remember what happened when they are not actively involved (Milner-Bolotin, Kotlicki, \& Rieger, 2007). Interactive lecture Experiments (ILEs) have been developed to address this problem (Sokoloff, Thornton, \& Laws, 2004). This pedagogy facilitates student involvement with demonstrations and promotes better and deeper conceptual understanding. A handful of researchers have focused on the design and implementation of various active learning environments in physics education research projects aimed to stimulate student learning and satisfaction with physics courses (Duncan, 2005; Hake, 1998; Mazur, 1997).

Classroom experiments offer a way to teach important ideas and concepts. The premise behind conducting classroom experiments is that by actively participating in an experiment, students will be better equipped to understand the concept being demonstrated. Although no conventional definition of exactly what constitutes a classroom experiment appears to exist, Barnett and Kriesel (2003) proposed that classroom experiments should meet the following three conditions: (1) the activity is conducted primarily for instructional purposes to demonstrate specific concepts, (2) the activity involves participants making decisions within a somewhat controlled environment, and (3) participants' decisions are compared to behavioral hypotheses derived from theory. The authors claim these conditions distinguish classroom experiments from other active learning techniques (e.g., case studies, role-playing, simulations).

Classroom experiments also offer the added benefit of being enjoyable or serving as an ice breaker that initiates discussion and subsequent student involvement in class (Cartwright \& Stepanova, 2009). However, for students to participate in a classroom experiment is simply not enough; students also need to be given the opportunity to engage in discussion and reflect on their experience to fully appreciate the message and truly facilitate learning. Another benefit of conducting mini-experiments is that it shifts the classroom from an instructorcentered environment to a learner-centered one. Active participation in experiments engage students and require them to use cognitive and conceptual skills that can serve as meaningful learning experiences and provide with a solid foundation for further inquiry (Straits \& Wilke, 2006).

Although many of the studies that have focused on the use of classroom experiments have occurred in economics courses, classroom experiments can be used in many disciplines (e.g., politics, psychology, physiology, mathematics, physics). For instance, Draper (2008) suggests that a range of experiments can be demonstrated using students as participants, using audience response systems, in topics that concern human responses. For example, in psychology, when demonstrating conformity, the responses to early questions could be simulated in order to see whether the class would change their answers to match earlier responses. The great advantage of using classroom 
experiments is that every audience member gets an opportunity to experience what it is like to be a subject in the experiment as well as how variable the range of responses can be. In addition, students can also see how their own responses compare to the average. This experience cannot be achieved using the traditional, passive lecture technique or by simply reading from a textbook. See Draper (2008) for ideas on how to apply experiments in different disciplines.

Classroom experiments have been found to positively affect test scores (Dickie, 2006; Durham, McKinnon, and Schulman, 2007; Emerson \& Taylor, 2004). Additionally, Durham et al (2007) found the data suggest that the benefit of classroom experiments varies depending on a student's preferred learning style: kinesthetic and multimodal learners were significantly positively affected by the use of classroom experiments (Dufwenberg \& Swarthout, 2009). One main reason experiments are effective is because students can be placed directly into the environment being studied and after participating, they then bring first-hand experience to the discussion (Holt, 1999).

Classroom experiments present many similar benefits as other active learning techniques. Experiments provide tangible examples of theoretical concepts (Adams and Kluger, 1998; Dobbins et al., 1995; Stephenson and Langdon, 1997; Walker, 1987; Wells, 1991). They also create an active learning environment of self-discovery and hence, follow the constructivism philosophy (DeYoung, 1993; Stephenson and Langdon, 1997; Walbert and Bierma, 1988; Wells, 1991). Additionally, they can cause students to think of questions that they might not otherwise have considered if presented in a traditional lecture format (Dobbins et al., 1995; Wells, 1991) and they have been shown to increase student enthusiasm and interest (Stephenson and Langdon, 1997; Walker, 1987). Experiments provide immediate feedback on what concepts students do and do not understand (Wells, 1991) and facilitate retention of essential concepts (Walbert and Bierma, 1988).

Although classroom experiments offer many benefits, there is a concern about the opportunity cost of using them. They can take up valuable and limited classroom time that could be used to cover other material (Bell, 1993; Wells, 1991). Haupert (1996), however, maintains that a good experiment greatly reduces the number of examples needed to explain a concept and thus may actually reduce the amount of time needed to cover a particular topic. Additionally, the set up time, can require a significant amount of time outside of class (Bell, 1993), however, the time required to construct an experiment is largely a one-time, fixed cost.

\section{Using An Audience Response System}

Technological advances have created an opportunity by which instructors can simply, efficiently, and effectively incorporate mini-experiments into the classroom and allow the system to help facilitate interactive teaching and improve the quality of learning. An Audience Response System (ARS) is a wireless response system that allows students to participate by submitting responses to interactive questions using a hand-held response pad to send information to a receiver. The computer instantaneously records individual responses and displays the response on a projection screen, usually in the form of a histogram or bar graph (Micheletto, forthcoming).

Using an ARS has been found to improve classroom interaction (Hoekstra, 2008; Zhu, 2007) encourage student engagement with course content (Bode, Drane, Kolikant, \& Schuller, 2009; Robinson \& Ritzko, 2006), and promote a more learner-centered, active learning environment as compared to traditional, passive learning, lecturebased instruction (Caldwell, 2007; Crouch \& Mazur, 2001; Hoffman \& Goodwin, 2006). By using an ARS, each student is given the opportunity to respond electronically (often times anonymously) to a variety of types of questions posed by the instructor (e.g., multiple choice, true/false, Likert scale). This method of instruction creates a more active classroom environment where every student can participate and play a role in the activity and classroom discussion (Rodgers \& Starrett, n.d.). See Kay and LaSage (2009) for a thorough literature review regarding the benefits of using an ARS.

Using an ARS to replicate theoretical studies, actual real-world survey data, and/or social or economic experiments is beneficial as each student has the ability to be an active participant in the "study," the results are displayed instantly (no need for the pen/paper method that requires out of class tabulation), and it allows for immediate discussion. Additionally, student's reflection of their experience in the experiment is a great way to 
encourage active learning and promote deeper, critical thinking. Because the ARS can be used with PowerPoint, with a little forethought and work upfront, an ARS can be easily set up to demonstrate many different types of experiments.

\section{THE EXPERIMENT: DEMONSTRATING THE ISOLATION EFFECT}

\section{Materials}

The TurningPoint ${ }^{\mathrm{TM}}$ audience response system by Turning Technologies (Turning Technologies, LLC, Youngstown, OH, USA) was used for the two mini-experiments. The TurningPoint ${ }^{\mathrm{TM}}$ audience response system consists of a set of ResponseCards ${ }^{\circledR}$ (handheld devices with keypads), a USB transceiver, and software that integrates with Microsoft ${ }^{\circledR}$ PowerPoint ${ }^{\circledR}$. Additionally, a computer, with a USB connector for the ARS receiver, was used to capture the data and a projection screen was used to project the questions and a histogram of the responses. The TurningPoint ${ }^{\mathrm{TM}}$ software allowed for integration of the results with Microsoft Office ${ }^{\circledR}$ so the results could be automatically displayed within a PowerPoint ${ }^{\circledR}$ presentation and responses were tracked and recorded via Excel ${ }^{\circledR}$. (http://www.turningtechnologies.com).

\section{Description Of Concept}

The Isolation Effect (AKA, Von Restorff effect - named after Hedwig von Restorff), refers to the notion that a stimulus will appear more attractive if/when it is placed next to an alternative stimulus that is less attractive than when it presented by itself. For example, a product that is priced relatively high, will appear more attractive when placed on a shelf next to another product whose product is more expensive. This effect is used quite often in advertising where before and after photographs are used to illustrate the impact a product (e.g., diet pill, exercise equipment, diet plan, shampoo/conditioner, anti-aging products) has had on the consumer using the product. By showing the before and after shots side by side, the "after" shot will appear more attractive, and subsequently, the "before" shot will appear less attractive.

\section{Preparing The Experiment}

Find three "Before" and "After" pictures on the Internet. Open up a new TurningPoint ${ }^{\mathrm{TM}}$ presentation and using a PowerPoint ${ }^{\mathrm{TM}}$ slide, insert each picture on a blank slide based on the information provided in Table 1 (which picture(s) each group will see and whether they are rating the "before" or "after" shot). The first two groups will see only the "before" or the "after" shot and will rate that particular picture. The last two groups will see both pictures, side by side, but will only rate either the "before" or the "after" shot. Before each set of pictures for each group, insert a slide that dilineates the rating scale (see Figure 1 and 2). Note that these rating scale slides will be the same for Groups 1 and 2 (see Figure 1) and different for Groups 3 and 4 (see Figure 2).

Table 1: Presentation Slide Arrangement

\begin{tabular}{|l|l|l|l|l|l|l|l|l|l|}
\hline Group \# & Picture(s) & Picture(s) & \multicolumn{1}{l|}{ Picture(s) } \\
\hline & Person & B or A & Rate & Person & B or A & Rate & Person & B or A & Rate \\
\hline 1 & Person 1 & B & B & Person 2 & B & B & Person 1 & A & A \\
\hline 2 & Person 2 & A & A & Person 3 & B & B & Person 3 & A & A \\
\hline 3 & Person 1 & B\&A & A & Person 2 & B\&A & A & Person 3 & B\&A & A \\
\hline 4 & Person 1 & B\&A & B & Person 2 & B\&A & B & Person 3 & B\&A & B \\
\hline
\end{tabular}




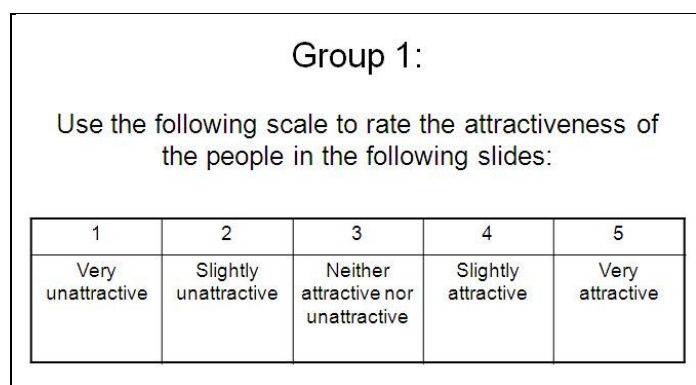

Figure 1: Rating Scale Slide For Groups 1 (And 2)

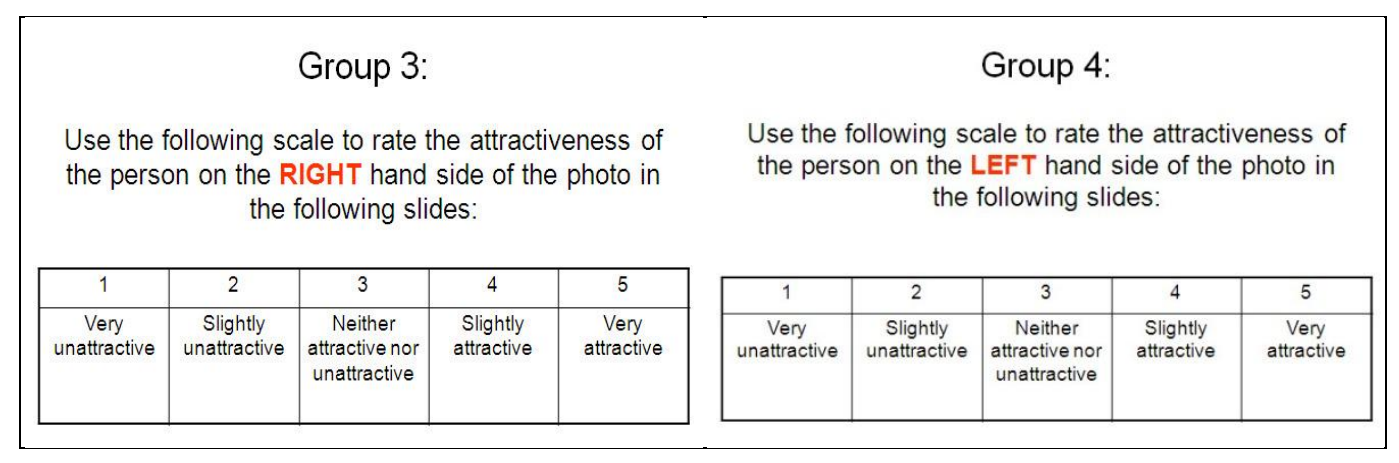

Figure 2: Rating Scale Slides For Groups 3 \& 4

Using TurningPoint ${ }^{\mathrm{TM}}$ software, insert a Likert Scale slide after each picture slide (see Figures 3-6). TurningPoint $^{\mathrm{TM}}$ offers the option to use a 4-, 5-, or 7-point Likert scale. Adjust the wording of the Likert scale to correspond to what it being asked in your particular experiment. For example, in this experiment a 5-point Likert scale was used (1=Very Unattractive, 2=Slightly Unattractive, 3=Neither Unattractive nor Attractive, 4=Slightly Attractive, 5=Very Attractive). Include a blank slide in between each group's session to give the students and the instructor a visual cue that the previous session is over and the next group is on deck (see Table 2). After the initial slides are set up, at the end of the presentation, insert comparative links slides to display the results from two separate slides on one slide (see Figures 7-9). To illustrate the Isolation Effect, the solo "After" slide results were compared to the "After" slide results when both the Before and After photos were displayed (see slides 42-46 in Table 3). However, as the data has already been collected, it is possible to show other comparisons as well (i.e., solo "Before" to solo "After," solo "Before" to "Before" when both the Before and After photos were displayed).

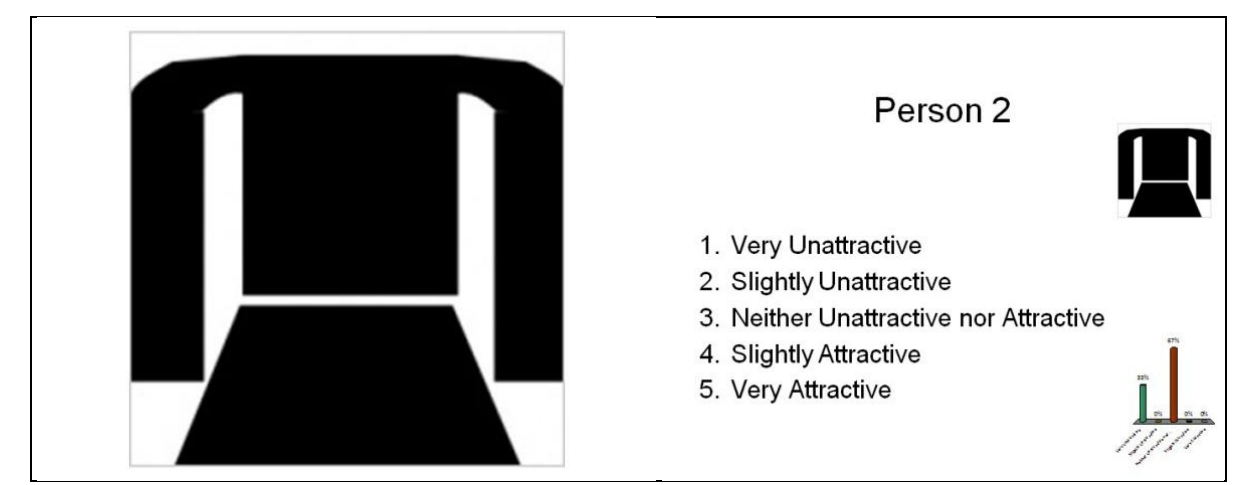

Figure 3: Picture Slide \& Rating Slide (Group 1); Person 2 - Before Picture (Rate Before) 


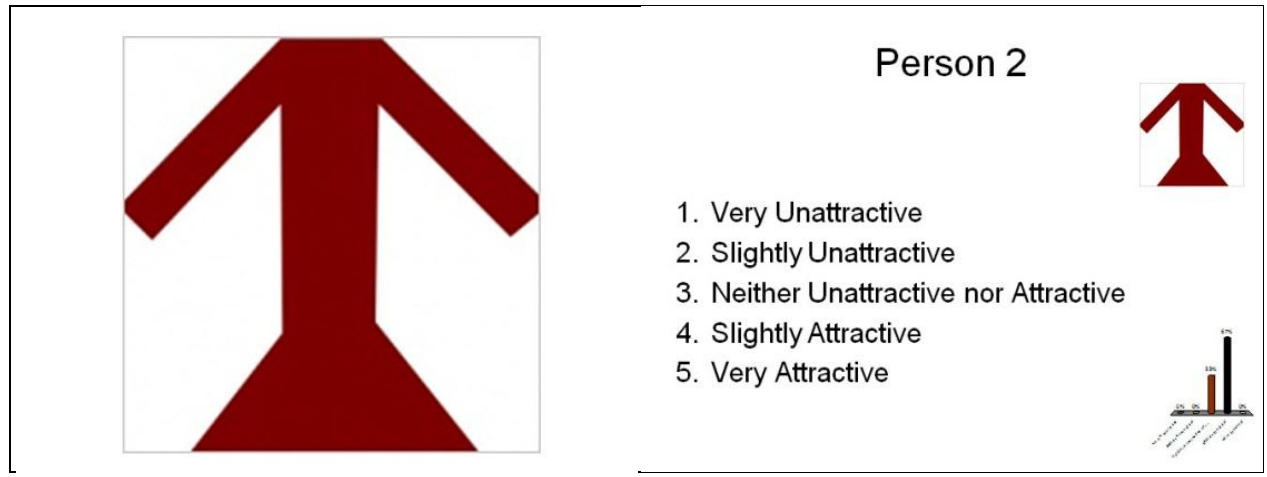

Figure 4: Picture Slide \& Rating Slide (Group 1); Person 2 - After Picture (Rate After)

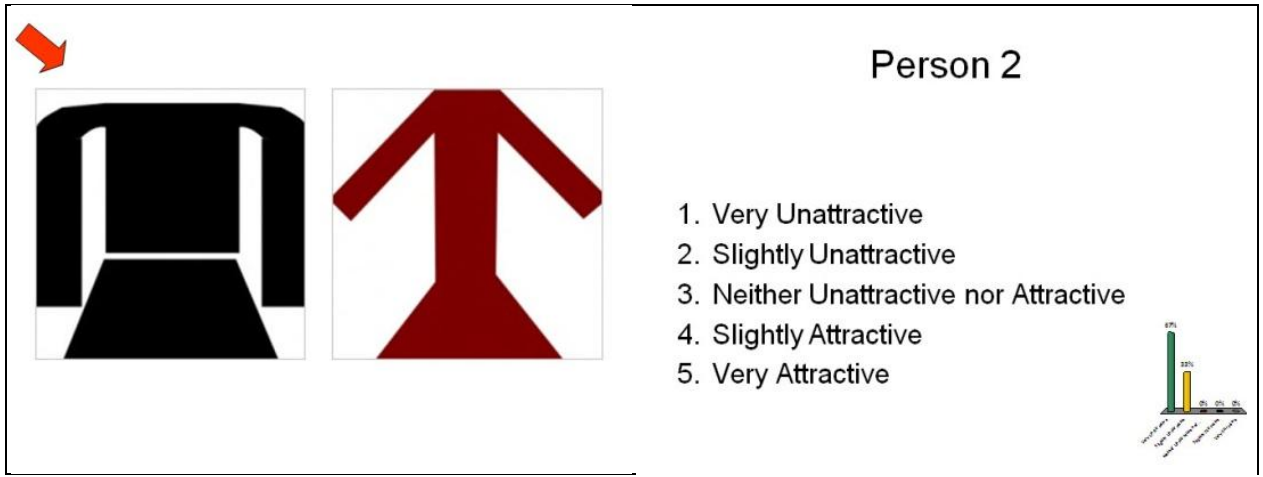

Figure 5: Picture Slide \& Rating Slide (Group 3); Person 2 - Both Before \& After Pictures (Rate Before)

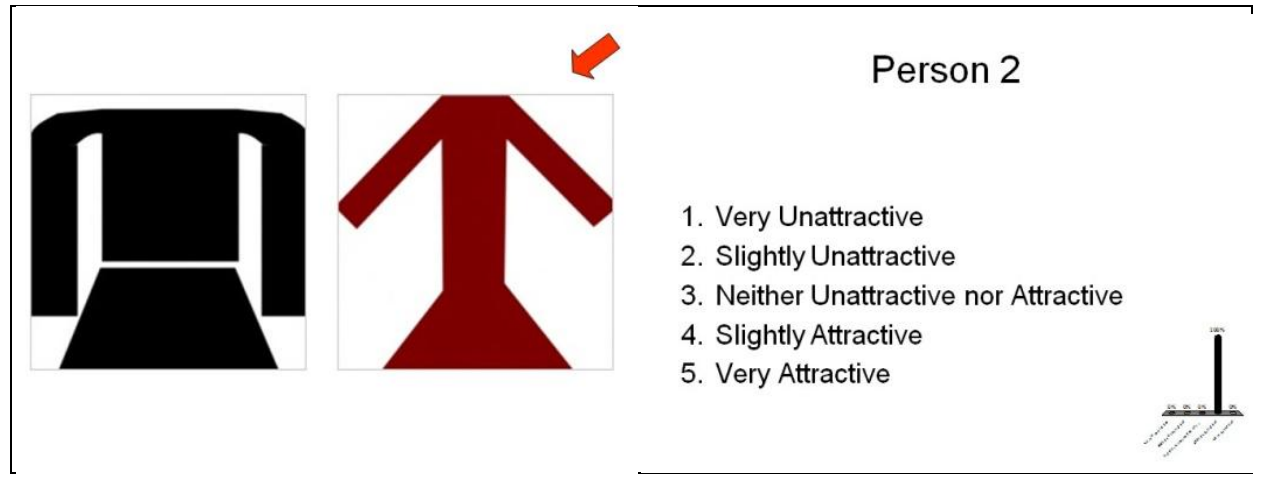

Figure 6: Picture Slide \& Rating Slide (Group 4); Person 2 - Both Before \& After Pictures (Rate After) 
Table 2: Order And Content (Type) Of Data Collection Slides

\begin{tabular}{|l|l|l|l|l|l|l|l|}
\hline$\#$ & Slide Content & $\#$ & Slide Content & $\#$ & Slide Content & $\#$ & Slide Content \\
\hline 1 & Blank slide & 10 & Blank slide & 19 & Blank slide & 28 & Blank slide \\
\hline 2 & "Group \#1" & 11 & "Group \#2" & 20 & "Group \#3" & 29 & "Group \#4” \\
\hline 3 & $\begin{array}{l}\text { Overall rating scale } \\
\text { slide }\end{array}$ & 12 & $\begin{array}{l}\text { Overall rating scale } \\
\text { slide }\end{array}$ & $\begin{array}{l}\text { Overall rating scale } \\
\text { slide (After) }\end{array}$ & 30 & $\begin{array}{l}\text { Overall rating } \\
\text { scale slide (Before) }\end{array}$ \\
\hline 4 & Picture & 13 & Picture & 22 & Pictures (B\&A) & 31 & Pictures (B\&A) \\
\hline 5 & $\begin{array}{l}\text { Rating slide (Likert } \\
\text { scale) }\end{array}$ & 14 & $\begin{array}{l}\text { Rating slide (Likert } \\
\text { scale) }\end{array}$ & 23 & $\begin{array}{l}\text { Rating slide (Likert } \\
\text { scale) }\end{array}$ & 32 & $\begin{array}{l}\text { Rating slide } \\
\text { (Likert scale) }\end{array}$ \\
\hline 6 & Picture & 15 & Picture (B) & 24 & Pictures (B\&A) & 33 & Pictures (B\&A) \\
\hline 7 & $\begin{array}{l}\text { Rating slide (Likert } \\
\text { scale) }\end{array}$ & 16 & $\begin{array}{l}\text { Rating slide (Likert } \\
\text { scale) }\end{array}$ & 25 & $\begin{array}{l}\text { Rating slide (Likert } \\
\text { scale) }\end{array}$ & 34 & $\begin{array}{l}\text { Rating slide } \\
\text { (Likert scale) }\end{array}$ \\
\hline 8 & Picture & 17 & Picture & 26 & Pictures (B\&A) & 35 & Pictures (B\&A) \\
\hline 9 & $\begin{array}{l}\text { Rating slide (Likert } \\
\text { scale) }\end{array}$ & 18 & $\begin{array}{l}\text { Rating slide (Likert } \\
\text { scale) }\end{array}$ & $\begin{array}{l}\text { Rating slide (Likert } \\
\text { scale) }\end{array}$ & 36 & $\begin{array}{l}\text { Rating slide } \\
\text { (Likert scale) }\end{array}$ \\
\hline
\end{tabular}

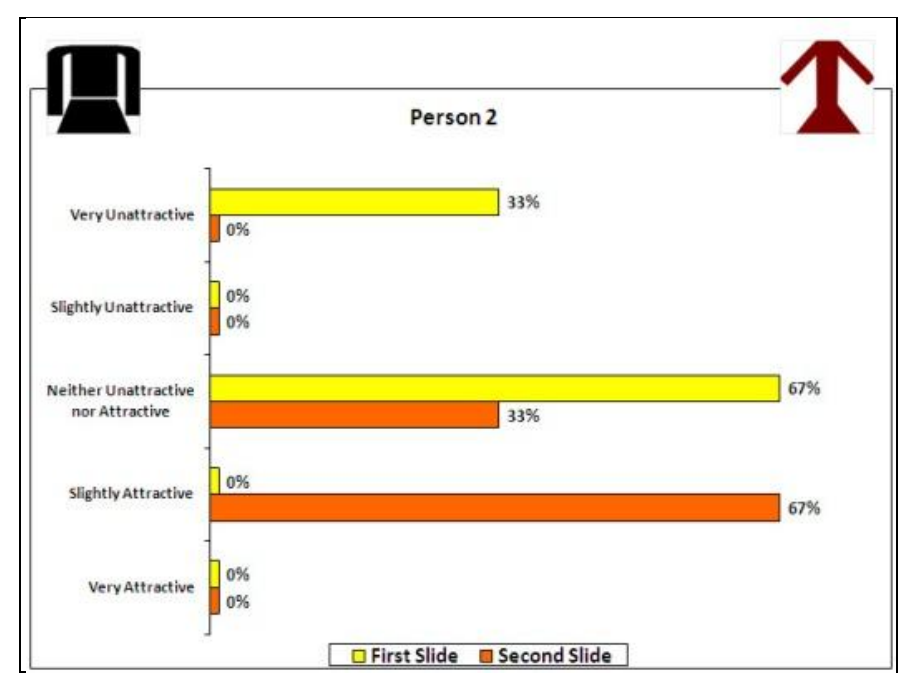

Figure 7: Comparison Slide. This figure presents the results of rating the solo Before photo to the solo After photo.

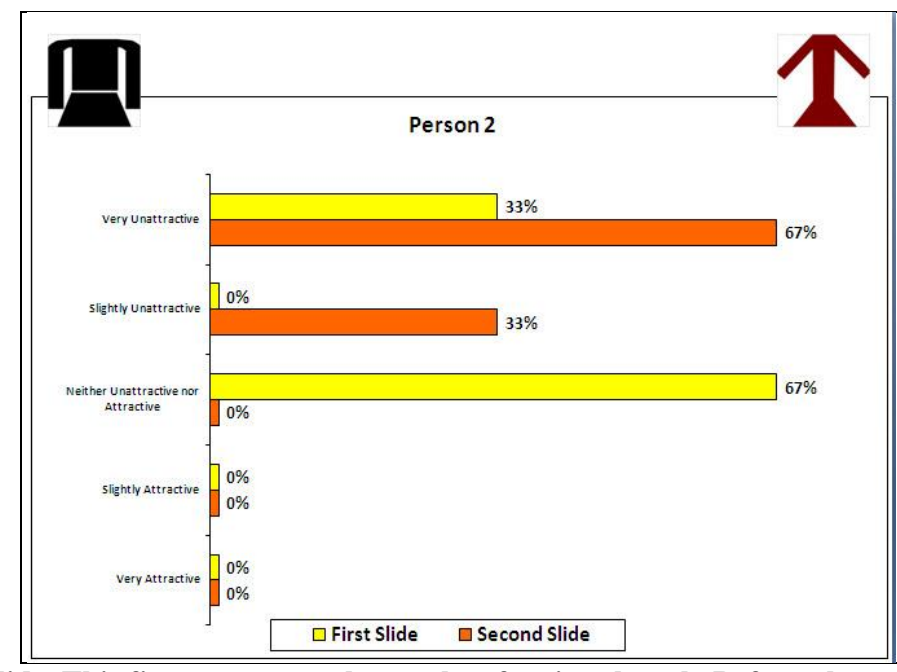

Figure 8: Comparison Slide. This figure presents the results of rating the solo Before photo to Before photo when both before and after photos were displayed. 


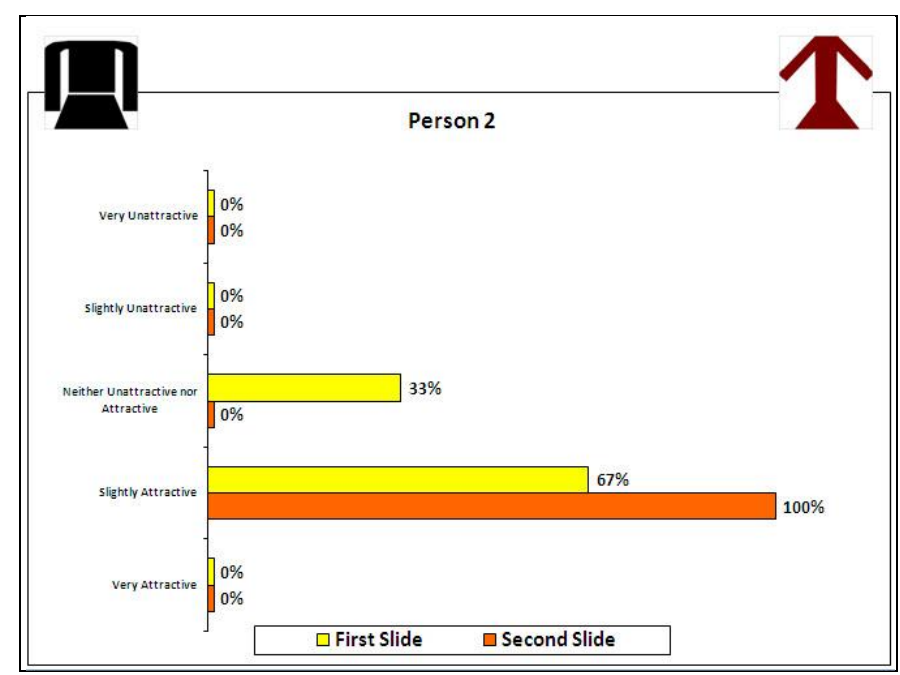

Figure 9: Comparison Slide. This figure presents the results of rating the solo After photo to the After photo when both Before and After photos were displayed.

Table 3: Order And Content (Type) Of Results Slides

\begin{tabular}{|l|l|l|l|l|l|}
\hline$\#$ & Slide Content & $\#$ & Slide Content & $\#$ & Slide Content \\
\hline 37 & Blank slide & 42 & Blank slide & 47 & Blank slide \\
\hline 38 & "Comparing Before to After" & 43 & $\begin{array}{l}\text { "Comparing After to After of } \\
\text { Before \& After" }\end{array}$ & 48 & $\begin{array}{l}\text { "Comparing Before to Before of } \\
\text { Before \& After" }\end{array}$ \\
\hline 39 & Person 1 (Comparative link) & 44 & Person 1 (Comparative link) & 49 & Person 1 (Comparative link) \\
\hline 40 & Person 2 (Comparative link) & 45 & Person 2 (Comparative link) & 50 & Person 2 (Comparative link) \\
\hline 41 & Person 3 (Comparative link) & 46 & Person 3 (Comparative link) & 51 & Person 3 (Comparative link) \\
\hline
\end{tabular}

\section{Conducting The Experiment}

Randomly assign students to one of four groups. Note, group sizes should be similar, but do not have to be equal. Each group participates only once, voting a total of three times, during the experiment (if three pictures or stimuli are used). It is highly recommended to collect data from the class in anonymous mode to ensure that students feel comfortable participating in the experiment. It is imperative that each group only view the photos for their group. The students are very good about closing their eyes or turning around so they cannot view what another group is doing. After each group has "voted" it is fine if they now view the subsequent group's part of the exercise, as long as they do not discuss or somehow divulge what they will begin to realize as the experiment continues. After all four groups have rated their respective photos, have everyone open their eyes as the comparative links slides are revealed. It may take some time to get through the first few comparative links slides as the students learn how to read the graph. A quick explanation may be in order at this point. However, it is important to allow enough time for the students to absorb the information and reflect upon what they are seeing and learning. At this point, students could be asked to explain what the graph is indicating and then open the floor for discussion about how and why this effect might be an effective technique in marketing to consumers. Additionally, students could be asked to brainstorm about areas outside of weight loss products that the Isolation Effect might have an impact in the marketplace.

\section{RESULTS/DISCUSSION}

In the scenario and data presented above, the Isolation Effect definitely had an impact on the student's perception and rating of the photos. While the actual percentages may or may not be necessarily important, the visual that is presented by the bar graphs on the comparative links slides certainly paints the picture that there were distinct differences in perception when photos were viewed by themselves or alongside another picture. 
In this case, with Person 2, the data from the comparative links slide that displays the discrepancy in rating the solo "After" picture and the "After" picture when both the Before and After photo were exposed. When the "After" photo was shown by itself, 33 percent of the students rated Person 2 as being "neither unattractive nor attractive" and 67\% rated Person 2 as being "somewhat attractive." However, when shown side by side, the same "After" photo of Person 2 was rated as "somewhat attractive" by 100 percent of the students. In other words, Person 2 was perceived as being more attractive when her "After" photo was shown beside her "Before" photo.

The comparative links slide that displays the discrepancy in rating the solo "Before" picture and the "Before" picture when both the Before and After photo were exposed, also reveals interesting and relevant data. When the "Before" photo was shown by itself, 33 percent of the students rated Person 2 as being "very unattractive" and $67 \%$ rated Person 2 as being "neither unattractive or attractive." However, when shown side by side, the same "Before" photo of Person 2 was rated as "very unattractive" by 67 percent of the students and "slightly unattractive" by 33 percent of the students. In other words, Person 2 was perceived as being more attractive in her "Before" photo and when shown beside her "After" photo, she was viewed as less attractive.

Additionally, data collected in the same experiment with another Before and After photo (Person 1), revealed that when the "After" photo was shown by itself, 33 percent of the students rated Person 1 as being "neither unattractive nor attractive" and 67 percent rated Person 1 as being "somewhat attractive." However, when shown side by side, the same "After" photo of Person 1 was rated as "somewhat attractive" by 67 percent of the students and as "very attractive" by 33 percent of the students. This reveals the same conclusion as Person 2 above. Person 1 was perceived as being more attractive when her "After" photo was shown beside her "Before" photo.

Although the Isolation Effect is not an extremely difficult concept to grasp, often times students are either indifferent about the concept or are skeptical that it really works when simply presented with the description of the effect in a lecture format. By using an audience response system that allows the students to be active participants, their collective responses give visual "proof" that the theory does hold true. Additionally, in the past, this type of experiment could be done via pencil and paper method, however, tabulating the results would either take precious class time or would be done out of class and the results presented the next class period. The audience response system allows for immediate feedback and discussion of the results. This also allows for additional discussion of how this particular strategy, now that they see it does work, can be applied in other areas.

Of course, as an instructor, it is essential to prepare an explanation in the event the results from the classroom mini-experiment do not replicate other studies or theories. This could certainly be explained by demographic differences in testing samples. For example, if the experiment is set up to replicate a real-world study on drug use or cigarette smoking habits, the real-world data may have been collected from younger, high-school aged or older respondents or there may be differences in socio-economic status. Although the classroom data may not correlate exactly to outside data sources, it undoubtedly offers opportunities for discussion and learning.

\section{CONCLUSION/IMPLICATIONS}

Although this article focused on using an ARS to implement one type of classroom mini-experiment, it could certainly be used to demonstrate many other concepts and theories or to replicate real-world studies that have been conducted (e.g., psychology, politics, math, sociology, and physics). For instance, perception of credibility of a source could be measured by altering the sources physical appearance (e.g., height, hair color, weight, attire) or an experiment could be set up to measure how students are spending their time (e.g., watching TV, sleeping, engaging in volunteer activities, exercising) and then compare these results to national survey results. The same could be done with drinking, smoking, or fast-food consumption activities. Each of these mini-experiments could also include demographic questions (e.g., age, gender) which could then be used to illustrate how different demographic groups compare to national survey results as well as differences within the classroom. Again, the use of the anonymous mode is critical to ensure honest and candid answers.

This article introduced one way in which to use an audience response system (ARS) to conduct a miniclassroom experiment to demonstrate a specific psychological concept, the Isolation Effect. By allowing students to be active participants in an experiment, not only gives them the experience of participation, but also teaches the 
value of interpreting, understanding, and reflecting upon the data. An ARS is a great pedagogical tool to demonstrate a concept and encourage active engagement, open discussion, personal reflection, and learning. Though the results revealed from the basic Likert scale questions were revealing, it is the comparative links feature of the ARS that enables the students to visually comprehend the message the data revealed and the instructor to facilitate the impending discussion by posing important questions.

\section{AUTHOR INFORMATION}

Melinda Micheletto is currently an Associate Professor at Saint Michael's College in Colchester, Vermont. She earned her Ph.D. from the University of Tennessee. As an educator, Melinda utilizes different teaching techniques to motivate her students and assist them in the learning process and is actively engaged in classroom activities that utilize innovative pedagogical tools. Melinda has become increasingly technologically driven in the classroom, collaborating with Instructional Technology to promote the use of several technologically-based pedagogies. She also employs hand-on, active learning activities and has recruited nearly 30 local, small, or not-for-profit organizations for student-based projects. Email: $\underline{\text { mmicheletto@ } \text { smcvt.edu }}$

\section{REFERENCES}

1. Adams, P. D. \& Kluger, B. D. (1998). Illustrating concepts of arbitrage, risk, and market efficiency: A classroom asset market, Financial Practice and Education, 8, 102-110.

2. Anthony, G. (1996). Active learning in a constructivist framework, Educational Studies in Mathematics, 31(4), 349-369

3. Barnett, B. J. \& Kriesel, W. (2003). Agricultural economists' use of classroom economic experiments, Journal of Agricultural and Applied Economics, 35(2), 321-335.

4. Bell, C.R. (1993).A noncomputerized version of the williams and walker stock market experiment in a finance course, Journal of Economic Education, 24, 317-323.

5. Beichner, R.J. (1993). A multimedia editing environment promoting science learning in a unique setting: A case study, Proceedings of Ed-Media 93World Conference on Educational Multimedia and Hypermedia, Orlando, Florida, 60, (June).

6. Bode, M., Drane, D., Kolikant, Y., \& Schuller, M. (2009). A clicker approach to teaching calculus. Notices of the American Mathematical Society, 56(2), 253-256.

7. Brooks, J. G. \& Brooks, M. G. (1993). In Search of Understanding: The Case for Constructivist Classrooms. Alexandria, VA: Association for Supervision and Curriculum Development.

8. Caldwell, J. (2007). Clickers in the large classroom: Current research and best-practice tips. CBE-Life Sciences Education, 6, 9-20.

9. Cartwright, E. \& A. Stepanova. (2009). Case Study in Assessment Practice: using classroom experiments in teaching Economics, Department of Economics, University of Kent.

10. Constructing knowledge in the classroom, (1994). Classroom Compass, 1(3). Retrieved from http://www.sedl.org/scimath/compass/v01n03/2.html

11. Cooperstein, S.E. \& Kocevar-Weidinger, E. (2004). Beyond active learning: a constructivist approach to learning, Reference Services Review, 32(2), 141-148

12. Crouch, C. H., Fagen, A. P., Callan, J. P. \& Mazur, E. (2004). Classroom demonstrations: Learning tools or entertainment? American Journal of Physics, 72(6), 835-838. doi:10.1119/1.1707018.

13. Crouch, C. H. \& Mazur, E. (2001). Peer instruction: Ten years of experience and results. American Journal of Physics, 69, 970-977.

14. Dewey, J. (1916). Democracy and Education. New York: Free Press.

15. DeYoung, R. (1993). Market experiments: The laboratory versus the classroom, Journal of Economic Education, 24(1993), 335-351.

16. Dickie, M. (2006). Do classroom experiments increase learning in introductory microeconomics? Journal of Economic Education, 37, 267 - 288.

17. Dobbins, C. L., Boehlje, M., Erickson, S. \& Taylor, R. (1995). Using games to teach farm and agribusiness management, Review of Agricultural Economics, 17, 247-55.

18. Draper, S. (2008). Pedagogical formats for using questions and voting. Retrieved from http://www.psy.gla.ac.uk/ steve/ilig/qpurpose.html 
19. Dufwenberg M. \& Swarthout, J. T. (2009). Play to learn? An experiment, Experimental Economics Center Working Paper Series 2009-08, Experimental Economics Center, Andrew Young School of Policy Studies, Georgia State University.

20. Duncan, D. (2005). Clickers in the classroom. Pearson Education: Boston.

21. Durham, Y., McKinnon, T. \& Schulman, C. (2007). Classroom experiments: Not just fun and games, Economic Inquiry, 45, 162-178.

22. Emerson, Tisha L.N. \& Taylor, B. A. (2004). Comparing student achievement across experimental and lecture-oriented sections of a principles of microeconomics course, Southern Economic Journal, 70, 67293.

23. Felder, R. M., Forrest, K. D., Baker-Ward, L., Dietz, E. J. \& Mohr, P. H. (1993). A longitudinal study of engineering student performance and retention: Success and failure in the introductory course, Journal of Engineering Education, 82(1), 15-21.

24. Hake, R. R. (1998). Interactive-engagement versus traditional methods: A six-thousand student survey of mechanics test data for introductory physics courses, American Journal of Physics, 66(1), 64-74. doi:10.1119/1.18809.

25. Haupert, M. J. (1996). An experiment in comparative advantage, Journal of Economic Education, 27, 3744.

26. Hoekstra, A. (2008). Vibrant student voices: Exploring effects of the use of clickers in large college courses. Learning, Media, and Technology, 33(4), 329-41.

27. Hoffman, C. \& Goodwin, S. (2006). A clicker for your thoughts: Technology for active learning. New Library World, 107(1228/1229), 422-433.

28. Holt, C. E. (1999). Teaching economics with classroom experiments, Southern Economic Journal, 65(3), 603-610.

29. Holzer, S. M. (1994). From constructivism to active learning, The Innovator, Spring (2). Retrieved from: http://www.succeed.ufl.edu/innovators/innovator_2/innovator002.html

30. Kay, R. H. \& LaSage, A. (2009). Examining the benefits and challenges of using audience response systems: A review of the literature. Computers \& Education, 53, 819-829.

31. Kolb, D. A. (1984). Experiential Learning, Englewood Cliffs, NJ: Prentice Hall.

32. Koontz, S. R., Peel, D. S., Trapp, J. N., Ward, C. E. (1995). Augmenting agricultural economics and agribusiness education with experiential learning, Review of Agricultural Economics, 17, 267-274.

33. Laws, P. (1991). Workshop physics: Learning introductory physics by doing it, Change, 20(July/August).

34. Lumsdaine, E. \& Voitle, J. (1993). Contextual problem solving in heat transfer and fluid mechanics, AIChE Symposium Series, 89, 540.

35. Mazur, E. (1997). Peer instruction: User's manual. Prentice Hall, Upper Saddle River, N.J.

36. Micheletto, M. (forthcoming). Using audience response systems to encourage student engagement and reflection on ethical orientation and behavior, College Teaching Methods \& Styles Journal.

37. Milner-Bolotin, M., Kotlicki, A., \& Rieger, G. (2007). Can students learn from lecture demonstration? The role and place of interactive lecture experiments in large introductory science courses, Journal of College Science Teaching, 37(Jan-Feb), 45-49.

38. Moll, R. F. \& Millner-Bolotin, M. (2009). The effect of interactive lecture experiments on student academic achievement and attitudes towards physics, Canadian Journal of Physics, 87, 917-924. doi:10.1139/P09-048

39. Nattiv, A. (1994). 111 Active Learning Strategies: Applications for Higher Learning, Eastern New Mexico University: Centers for Teaching Excellence.

40. Piaget, J. (1973). To understand is to invent. New York: Grossman.

41. Robinson, S. \& Ritzko, J. (2006). Increasing student engagement through electronic response devices. Proceedings of the Academy for Educational Leadership, 11(1), 79-82.

42. Rodgers, M. L. \& Starrett, D. A. Calling All Students...Come in. Students..., UC Riverside

43. Roth, W. M., McRobbie, C. J., Lucas, K. B. \& Boutonne', S. (1997). Journal of Research Science Teaching, 34, 509. doi:10.1002/(SICI)1098-2736(199705)34:5<509::AID-TEA6>3.0.CO;2-U.

44. Shneiderman, B. (1993). Education by engagement and construction: Experiences in the AT\&T teaching theater, Proceedings of Ed-Media 93World Conference on Educational Multimedia and Hypermedia, Orlando, Florida, 471, June.

45. Sokoloff, D. R., Thornton, R. K. \& Laws, P. W. (2004). Real Time Physics, John Wiley and Sons, Inc. 
46. Stephenson, K. \& Langdon, M. C. (1997). Learner-centered teaching approaches and classroom economic games: An example of a tradable pollution allowance simulation, Unpublished manuscript, Virginia Tech University, Blacksburg, VA, January 21.

47. Straits, W. J. \& Wilke, R. R. (2006). Interactive demonstrations: Examples from biology lectures, Journal of College Science Teaching, 35(4), 58-59.

48. Thompson, J. G. \& Jorgensen, S. (1989). How interactive is instructional technology? Alternative models for looking at interactions between learners and media, Educational Technology, 24(February).

49. von Glasersfeld, E. (1995). Radical constructivism: A way of knowing and learning, Washington, DC: The. Falmer Press.

50. Walbert, M. S. \& Bierma, T. J. (1988). The permits game: Conveying the logic of marketable pollution permits, Journal of Economic Education, 19, 383-89.

51. Walker, J. (1987). Experimental economics in the classroom, Journal of Economic Education, 18, 51-57.

52. Wells, D. A. (1991). Laboratory experiments for undergraduate instruction in economics, Journal of Economic Education, 22, 293-300.

53. Workshop: constructivism as a paradigm for teaching and learning, Concept to Classroom, Thirteen Ed Online. Retrieved from: http://www.thirteen.org/edonline/concept2class/constructivism/index.html

54. Zhu, E. (2007). Teaching with clickers. Center for research on learning and teaching occasional papers. 22. Retrieved from http://www.crlt.umich.edu/publinks/CRLT no22.pdf. 


\section{NOTES}

